\title{
Dinâmica Industrial e Cumulatividade Tecnológica: Uma Abordagem Evolucionária
}

\author{
Sérgio Almeida de Sousa
}

Doutorando em Economia pela

Universidade de Nottingham

\begin{abstract}
RESUMO
O objetivo deste artigo é aperfeiçoar o modelo evolucionário de dinâmica industrial proposto por Nelson e Winter (1982b), introduzindo algumas modificações analíticas no processo que define o resultado da busca tecnológica da firma. A modificação proposta visa introduzir um mecanismo que realimente positivamente (a partir do próprio histórico tecnológico da firma) o processo estocástico que define o resultado das tentativas das firmas de obterem inovações/imitações via gasto em P\&D. Com isso, pretende-se superar uma limitação que persiste mesmo nos modelos que trataram de superar outras simplificações do modelo e que ainda seguem muito de perto a formalização do processo de busca tecnológica do modelo Nelson-Winter. Por fim, tratar-se-á de apresentar algumas simulações preliminares que buscam avaliar as implicações dessa mudança no desempenho da indústria em geral e, em particular, para a estabilidade do desempenho competitivo das firmas em termos de market share.
\end{abstract}

\section{PALAVRAS-CHAVE}

modelo evolucionário de dinâmica industrial, cumulatividade tecnológica, simulação da dinâmica industrial

ABSTRACT

This paper's aim is to present a theoretical extension of the evolutionary model of industrial dynamics proposed by Nelson and Winter (1982b), introducing some analytical modifications in the process that defines the result of the firm's technological search. It is introduced a mechanism that positevely reinforces the random process that defines the result of the firms' attempts to make innovations/imitations by P\&D expenses. This new version intend to surpass a limitation persisting in the whole stream of evolutionary models. Although they have been eliminating other simplifications of the model, all of them still follow the Nelson-Winter model technological search process closely. Finally, it will be presented some preliminary simulations seeking to evaluate the implications of this change on the industry performance (price, productivity) and, particularly, on the stability of firms' competitive performance in terms of market share.

KEY WORDS evolutionary model of industrial dynamics, technological cumulativeness, simulation of industrial dynamics

JEL Classification

$\mathrm{LII}, \mathrm{O}$ II

EST. ECON., SÃO PAULO, V. 35, N. 4, P. 599-630, OUTUBRO-DEZEMBRO 2005 


\section{INTRODUÇÃO}

Embora a influência do progresso técnico nos padrões de concorrência entre as firmas e no crescimento de uma economia seja um aspecto comum na literatura econômica recente, Nelson e Winter haviam feito incursões no estudo das dimensões tecnológicas da competição desde o fim da década de setenta. (Cf. Nelson e Winter 1982b, 1980, 1978, 1976, 1973). A perspectiva evolucionária adotada não apenas parte dos processos microeconômicos de decisão no âmbito da competição entre as firmas nos mercados, mas procura fazê-lo em um ambiente marcado por diversidade comportamental e processos cumulativos de desajuste e instabilidade estrutural nas trajetórias tecnológicas que podem provocar uma profunda redefinição (endógena) da estrutura do mercado.

Entre os vários modelos que propuseram, o de dinâmica industrial com progresso técnico endógeno (Nelson e Winter, 1982a, cap. 12; doravante NW), pela influência que exerceu sobre toda uma corrente de modelos de dinâmica industrial, foi o que mais se difundiu, chegando inclusive a fornecer insights importantes sobre a relação entre o processo de mudança tecnológica e a estrutura de mercado. Outra versão do modelo (Winter, 1984) explora novas fontes de mudança técnica (entrada de novas firmas) e introduz algumas mudanças com a finalidade de dar flexibilidade aos processos decisórios ligados às estratégias de P\&D das firmas. A partir daí surgiram outros modelos que procuram remover suas simplificações mais evidentes e ampliar seu escopo de análise.

Todavia, limitações do modelo NW ligadas ao processo de busca ("search") tecnológica ainda estão presentes na corrente de modelos que se seguiram (Cf. Silverberg et al., 1988; Chiarommonte e Dosi, 1994; Kwasnicki, 1996; Winter et al., 2000; Possas, Koblitz et al., 2001). Como será visto mais adiante, por seguirem de perto a modelagem do modelo NW do processo de inovação das firmas, isto é, de como os gastos em P\&D determinam o sucesso do esforço inovador e o desempenho da tecnologia utilizada na produção, todos esses modelos não incorporam uma característica importante do processo inovador, a saber, a cumulatividade - aspecto já considerado fatos estilizados sobre o processo de P\&D. (Cf. Adams, 2000, Breschi, 2000; Malerba e Orsenigo, 1997 e Kay, 1988).

A introdução de cumulatividade no modelo NW permitira que (1) o esforço passado de P\&D e (2) a eficiência com que a firma vem desempenhando a atividade de P\&D, indicada pelo sucesso inovador maior ou menor de suas estratégias de inovação, tivessem influência sobre o ritmo de progresso técnico da firma. Vejamos mais de perto como os dois aspectos, logo acima referidos, resolvem limitações relevantes nos modelos evolucionários citados acima. Há dois problemas internos no processo de busca tecnológica à la Nelson-Winter. De um lado, o esgotamento instantâneo dos efeitos do esforço de P\&D no período em que são realizados. Isto é, o esforço de P\&D realizado 
no período $t-i$ não exerce efeito direto sobre as chances de sucesso tecnológico no período $t$, qualquer que seja o valor inteiro positivo de $i$. Segue logicamente daí que o progresso técnico da firma num período $t$ qualquer depende exclusivamente do esforço de P\&D realizado naquele período. É evidente que essa formulação implica, de um lado, a existência de uma espécie de descontinuidade contínua incompatível com a natureza cumulativa da atividade de P\&D e, de outro, a inexistência de um mecanismo formal de realimentação estritamente tecnológico. Embora exista uma realimentação positiva do potencial inovador ou imitativo da firma, ela não é tecnológica, isto é, ela não é diretamente derivada do sucesso tecnológico prévio, mas sim uma realimentação repleta de mediaçóes que a tornam, ao fim de tudo, muito mais próxima de uma espécie de efeito tamanho. ${ }^{1}$

Desse modo, a incorporação de cumulatividade pretende conferir maior consistência empírica ao modelo, de modo que seja possível avaliar como a incorporação de um mecanismo de realimentação positiva no processo de mudança técnica pode impactar o desempenho intertemporal das firmas e a dinâmica estrutural da indústria - o que será feito a partir de uma análise comparativa dos exercícios de simulação do modelo original com aqueles obtidos sob a versão que será proposta.

Além desta introdução, este artigo terá ainda outras seis seções. Na seção seguinte (1) será feita uma breve apresentação do modelo de concorrência schumpeteriana proposto por Nelson e Winter. Na seção 2 mostraremos suas limitações analíticas à luz das evidências empíricas. Na seção 3 serão feitas algumas observações sobre o significado analítico da idéia de cumulatividade tecnológica, não apenas para fundamentar nossa proposta, mas também para nos contrapormos ao tipo de cumulatividade existente originalmente no modelo Nelson-Winter, de natureza distinta daquela que estamos introduzindo no modelo. Na seção 4 desenvolveremos a idéia de competência tecnológica cuja formalização e incorporação ao modelo Nelson-Winter permitirá suprimir uma de suas deficiências, inclusive tornando path-dependent o processo de mudança tecnológica das firmas. Na quinta seção faremos alguns exercícios de simulação do modelo modificado no intuito de, comparando com os resultados obtidos originalmente, avaliar a sensibilidade das trajetórias, ao longo do tempo, de algumas variáveis indicadoras do desempenho da indústria (grau de concentração, produtividade e preço médio, market share). Por fim, segue uma breve conclusão sintetizando as principais implicações dos resultados obtidos.

1 Como, aliás, parece sugerir Coombs (1988, p. 299) e está explicitado em artigo anterior (Veja Nelson e Winter, 1977, p. 273); ou, ainda, se trata apenas de um market feedback. Essa aparente cumulatividade tecnológica do modelo NW, não bastasse derivar em grande parte da rigidez das estratégias de P\&D (cf. Almeida, 2004; cap. 2), tem por trás um ciclo de mediações que, embora não seja instantâneo, possui um timing provavelmente mais longo e carregado de condicionantes do que aquele presente no mecanismo de realimentação aqui proposto, de natureza tecnológica - e que não exclui ou invalida aquele. 


\section{UM MODELO EVOLUCIONÁRIO DE DINÂMICA INDUSTRIAL}

O modelo que apresentaremos em seguida é uma versão modificada do modelo proposto em Nelson e Winter (1982a, cap. 12), e que busca representar um processo dinâmico de concorrência com fundamentos evolucionários (mais adiante), focalizando as relações de causalidade existentes entre a estrutura do mercado, os gastos em P\&D e variáveis indicativas do desempenho da indústria. Antes, contudo, faremos uma breve exposição dos principais fundamentos teóricos do enfoque evolucionário.

\subsection{Racionalidade Sob Incerteza, Busca e Seleção}

O padrão de racionalidade predominante na literatura neo-schumpeteriana segue de perto a abordagem de Simon $(1978 ; 1987)$ para os problemas de decisão, baseados em comportamentos decisórios que sejam compatíveis com (1) a impossibilidade prática de um conhecimento completo acerca de todas as possibilidades de decisão, (2) com o fato de que nosso conhecimento das conseqüências que estão associadas a cada possível ação é fragmentário e (3) com o caráter imperfeito de qualquer tentativa de antecipação de certos eventos - nesse caso, corolário lógico de uma economia com agentes que decidem de forma autônoma e cujas decisões são interdependentes.

A idéia é que os agentes (firmas ou indivíduos) são estimulados pela (1) incerteza - tomada de decisóes com desconhecimento do comportamento presente das variáveis relevantes e impossibilidade de antever, mesmo em termos probabilísticos, eventos que possam influenciar as decisóes correntes; (2) pelas próprias limitaçôes cognitivas e computacionais na solução de problemas complexos; e (3) pela magnitude dos custos econômicos de coleta e processamento de informaçóes na tentativa de operar estratégias ótimas, para adotar uma conduta decisória que aponta mais para práticas rotineiras baseadas em regras simples do que para decisões baseadas em procedimentos de maximização de objetivos bem definidos - permitindo, assim, a emergência de diversidade comportamental. Desse modo, as rotinas representam processos relativamente automatizados cuja utilização procura simplificar as decisões, reduzindo o número de variáveis envolvidas e o custo no processamento, cálculo e gerenciamento das decisões.

Há ainda duas outras noções - bastante representativas da influência que recebe da Biologia evolucionista - que, em sua complementaridade, amparam o núcleo teórico evolucionário na tentativa de integrar a mudança técnica com a transformação estrutural da economia, a saber, as noçôes de busca (search) e seleção.

A busca tecnológica é o procedimento estratégico que a firma utiliza, e que é responsável pela introdução de inovações (lato sensu) que implicam mudanças nos processos 
técnico-produtivos ou mesmo em suas rotinas operacionais, ${ }^{2}$ sempre na perspectiva de obter vantagens competitivas que, se não chegam a melhorar seu desempenho no processo competitivo, ao menos permitam a manutenção de seu peso relativo dentro da indústria. A centralidade dos procedimentos de busca tecnológica deriva, não por acaso, de sua importância na criação endógena de assimetrias competitivas, resultantes do impacto diferenciado que o sucesso inovador/imitativo, traduzido essencialmente em vantagens de custo, possui sobre o desempenho das firmas ao longo do tempo. A diversidade entre as firmas que se origina dessas diferenças tecnológicas alimenta o processo seletivo que opera sobre um dado conjunto de características (tecnologias e estratégias) das firmas e influencia a própria velocidade e direção dos processos de mudança técnica, dentro e para além do "paradigma" tecnológico prevalecente.

A seleção, por sua vez, representa o mecanismo de validação e redirecionamento dos processos e resultados da busca que podem resultar em eliminação ou alteração de tecnologias/estratégias insatisfatórias. ${ }^{3}$ Os modelos tributários dessa corrente procuram tornar explícita a idéia de que a dinâmica competitiva nos mercados possui mecanismos intrínsecos - introdução de inovações, sua difusão via imitação e a existência de processos (por vezes imperfeitos) de aprendizado - que operam uma pressão seletiva sobre um conjunto de firmas marcado pela diversidade, (estratégica, de base técnica, de competências), provocando alterações ao longo do tempo nas características das firmas e de sua importância relativa no mercado.

Os mecanismos de seleção em economia, diferentemente da biologia evolucionista, não implicam, necessariamente, que as firmas - possíveis unidades de seleção ${ }^{4}-$ menos efi- $^{-}$ cientes serão eliminadas do mercado. O grau de "aptidão" (fitness) das firmas provavelmente será determinado por vários critérios (qualidade do produto, preços, atraso de entrega, grau de endividamento etc.) que, a despeito da possibilidade de conflitarem entre si, procuram refletir de algum modo a eficiência da firma na sua busca por oportunidades de lucro. Obviamente, os estímulos que induzem as firmas a se engajarem em processos de busca são fortemente influenciados por esses mesmos mecanismos de seleção. Vale notar que a interação de ambos os processos (busca e seleção) responde não apenas pela determinação do comportamento das firmas e dos resultados de mercado, mas, também, pela determinação endógena de processos de mudança estrutural na indústria - que em nada se assemelham a um processo de ajuste compensatório que

2 O componente de incerteza envolvido na busca, por exemplo, de novos procedimentos operacionais, não permite, obviamente, antecipar a superioridade destes com relação às rotinas até então utilizadas.

3 Ou seja, que náo produzam os resultados esperados em termos de lucratividade ou mesmo de participação de mercado, seja por obsolescência (caso das tecnologias), seja por inadequação resultante de cálculo equivocado por utilizar premissas (certo tipo de reação das firmas rivais ou cenários econômicos) falsas (caso das estratégias).

4 Uma discussão sobre as controvérsias em Biologia acerca da identificação dos níveis - e mesmo das unidades - de seleção pode ser encontrada em Pondé (2000, seção 2.1.2.). 
torna "homogêneo" o padrão de ação (e reação) das firmas de forma a produzir (ou fazer convergir a) algum tipo de estado estacionário no mercado.

\subsection{Pressupostos Teóricos}

Há sete hipóteses de ordem estrutural que ajudam a caracterizar a indústria e o próprio ambiente seletivo de operação das firmas no modelo:

(1) as firmas produzem um produto homogêneo - o que implica a impossibilidade de concorrência por diferenciação de produto;

(2) os preços praticados pelas firmas são determinados pela função preço-demanda da indústria;

(3) a firma $j$ opera com a sua melhor técnica $\left(t_{i, j}^{*}\right)$ disponível, dentro das opções do conjunto de possibilidades técnicas disponíveis no período $t, \mathrm{~T}_{\mathrm{j}}^{(\mathrm{t})}$; tal conjunto representa, na verdade, uma coleção de $n$ técnicas que a firma $j$ possui $\left(t_{i, j}\right)$, de modo que a cada técnica $i$ estará associado um nível de produtividade do capital, $A_{t_{i}}$. Tem-se então que,

$$
t_{i, j}^{*}=t_{p, j}\left(A_{t_{p}}\right) \in \mathrm{T}_{j}^{(t)} ; A_{t_{p}} \geq A_{t_{i}} \forall p \neq i \quad \text { onde } p=1, \ldots, n ; i=1, \ldots, n
$$

sendo possível definir um conjunto de índices $I_{n}=\{p \in \mathrm{N} ; 1 \leq p \leq n\}$ para indexar $\mathrm{T}_{\mathrm{j}}^{(\mathrm{t})}$ de forma que $\chi: I_{n} \rightarrow \mathrm{T}_{j}^{(t)}$ é uma bijeção para algum $n \in \mathrm{N}-$, o que implica que $\mathrm{T}_{\mathrm{j}}^{(\mathrm{t})}$, o conjunto de técnicas produtivas disponíveis à firma no período $t$, é limitado;

(4) conquanto existam diferenças de produtividade entre as técnicas disponíveis em toda a indústria, tais técnicas possuem invariavelmente retornos constantes de escala;

(5) a tecnologia de produção tem coeficientes fixos de insumo (no que seguem uma função de produção do tipo Leontief), não havendo, portanto, substituição direta de trabalho por capital; como se trata de uma tecnologia complementar, o nível de produção máximo é determinado sempre pelo estoque de capital que cada firma dispóe, sendo os insumos complementares necessários para cada unidade de capital os mesmos (Nelson e Winter, 1982a, p. 282); as hipóteses (5) e (4) podem ser conjuntamente formalizadas se supusermos que $v_{j t}$ é a relação capital-produto no período $t$ da firma $j$, teremos que 


$$
\begin{aligned}
& Q_{j, t}=\xi\left(\frac{K_{j, t}}{v_{j, t}}\right) \forall j=1, \ldots, n \text { onde } \\
& \xi: \mathfrak{R}_{+} \rightarrow \mathfrak{R}_{+} \mathrm{e} \xi(0)=0,
\end{aligned}
$$

como toda a técnica utilizada possui retornos constantes de escala,

$$
\xi\left(\mu \frac{K_{j, t}}{v_{j, t}}\right)=\mu Q_{j, t} \forall v_{j, t} ; j=1, \ldots, n \text { e } t \in \mathrm{N}
$$

(6) a oferta dos insumos complementares (trabalho, $\mathrm{L}^{s}$, e matérias-primas, $\mathrm{I}^{s}$ ) é suposta perfeitamente elástica; logo, os preços dos insumos são supostos constantes para a indústria, independentemente da magnitude das demandas da indústria $\left(\mathrm{L}^{d} \mathrm{e}\right.$ $\left.\mathrm{I}^{d}\right)$. Supondo, sem perda de generalidade, que, assim como o trabalho, as matériasprimas (insumo I) também são ofertadas por meio de um único mercado que pratica os preços $\mathrm{P}^{\mathrm{L}}$ e $\mathrm{P}^{\mathrm{I}}$, respectivamente, então:

$$
\begin{aligned}
& \mathrm{L}^{s}>0 ; \mathrm{P}^{\mathrm{L}}=\bar{\alpha} \forall 0<\mathrm{L}^{d}<\infty \quad(\bar{\alpha}>0) \mathrm{e} \\
& \mathrm{I}^{s}>0 ; \mathrm{P}^{\mathrm{I}}=\bar{\beta} \forall 0<\mathrm{I}^{d}<\infty(\bar{\beta}>0) ;
\end{aligned}
$$

(7) quanto às estratégias tecnológicas, as firmas dispõem de dois métodos de incremento da produtividade: gastos em P\&D imitativo (copiar processos) e/ou gastos em P\&D inovador ( $G_{i t}^{m}$ e $G_{i t}^{n}$, respectivamente), responsáveis pelo esforço de capacitação (para domínio, operacionalização e desenvolvimento da tecnologia) e elaboração de projetos que tornam factível a introdução de novas técnicas (stricto sensu) produtivas. Ambos os gastos em P\&D envolvem resultados incertos. Observe-se que a magnitude desses gastos refletirá o tamanho da firma, uma vez que é proporcional ao capital da firma:

$$
\begin{aligned}
G_{i, t}^{m} & =r_{i, t}^{m} K_{i, t} \\
G_{i, t}^{n} & =r_{i, t}^{n} K_{i, t}
\end{aligned}
$$

onde $r_{i, t}^{n}$ e $r_{i, t}^{m}$ representam os custos por unidade de capital com P\&D imitativo e inovador (na verdade, a parcela do estoque de capital que será gasto em P\&D); 
(8) de (5) e (6) segue que o custo por unidade de capital é constante, mas, por (7), segue que o custo por unidade de produto é variável, uma vez que a "descoberta" (via P\&D) de novas técnicas permite à firma incrementar o produto por unidade de capital.

\subsection{Módulos de Produção, Investimento e Busca Tecnológica}

O modelo está estruturado, basicamente, em três módulos. Em um módulo é descrito um processo econômico simplificado no qual o cálculo da produção da firma, da indústria, o preço, a estrutura de custos e os lucros líquidos são realizados. Em um segundo módulo formaliza-se o de busca tecnológica, que definirá, em um processo estocástico de dois estágios, os resultados alcançáveis em termos de produtividade pelo esforço de P\&D (inovador e/ou imitativo) das firmas. No terceiro módulo são indicadas a natureza e os determinantes (condições médias de concorrência e restriçốes de crédito) das decisões de investimento da firma.

Uma vez dados os vetores $\mathrm{A}^{(t)}$ e $\mathrm{K}^{(t)}$ que descrevem o estado da indústria (o produto por unidade de capital e o estoque de capital da firma, respectivamente) no início do período $t$, fica determinado o nível de produção de cada firma, bem como a produção total da indústria $\left(\hat{\mathrm{Q}}^{(t)}\right)$, calculada por agregação do nível de produção $\left(Q_{i t}\right)$ de cada uma das $n$ firmas da indústria. Sendo, em notação vetorial,

$$
\mathrm{A}^{(t)}=\left[A_{p j}^{t}\right] e \mathrm{~K}^{(t)}=\left[K_{j p}^{t}\right] ; p=1 e j=1, \ldots, n \text {. }
$$

Como as firmas operam plenamente toda a sua capacidade produtiva $(\rho=1)$, isto é,

$$
Q_{i, t}=Q_{i, t}^{\max }=A_{i, t}\left(\rho K_{i, t}\right)
$$

então

$$
\hat{\mathrm{Q}}^{(t)}=\mathrm{A}_{l \times n}^{(t)} \mathrm{K}_{n \times 1}^{(t)}=\sum_{i=1}^{n} A_{1 i} K_{i 1} ; A_{1 i} \in \mathrm{A}^{(t)} \vee K_{i 1} \in \mathrm{K}
$$

A indústria depara com uma função demanda (constante com elasticidade unitária ${ }^{5}$ ) contínua e decrescente $\Psi($.$) , de forma que toda a produção da indústria é vendida ao$ preço determinado pelas condiçốes de demanda - note que a formação dos preços não é firm specific:

5 A hipótese de elasticidade $(\varepsilon)$ unitária, com demanda constante, tem uma importante implicação: observe que

$\varepsilon=\frac{d Q}{d P} \frac{P}{Q}=1 \rightarrow \frac{d Q}{Q}=\frac{d P}{P}$

ou seja, os ganhos de produtividade (médios) são integralmente repassados para os preços. De certa forma, essa hipótese acaba por substituir as mediações que existiriam caso houvesse um mercado de trabalho. 


$$
P_{t}=\Psi\left(Q_{t}\right)
$$

onde

$$
P_{t} \in[0, \Psi(0)] ; \Psi(0)<\infty \text { e } \lim _{Q \rightarrow \infty} \Psi(Q)=0
$$

O lucro econômico da firma por unidade de capital é o resíduo da receita total por unidade de capital subtraída do custo total de produção por unidade de capital, incluídos os gastos com atividade de P\&D.

$$
\Pi_{i, t}=P_{t} A_{i, t}-\frac{1}{K_{i, t}}\left(C+G_{i, t}^{m}+G_{i, t}^{n}\right)
$$

O módulo de busca tecnológica, por sua vez, especifica os processos pelos quais as novas técnicas são "criadas" e como sua incorporação modifica a produtividade da firma e da indústria. A atividade inovadora é modelada como um processo estocástico de dois estágios, que irá definir os níveis de produtividade alcançáveis pela atividade de P\&D. No primeiro estágio são definidas as respectivas probabilidades de obtenção de sucesso inovador e imitativo - tanto maiores quanto maior o respectivo gasto (imitativo ou inovador) em $\mathrm{P} \& \mathrm{D}^{6}$ da firma,

$$
\begin{aligned}
& \operatorname{Pr}\left(d_{i, t}^{m}=1\right)=a^{m} G_{i, t}^{m} \\
& \operatorname{Pr}\left(d_{i, t}^{n}=1\right)=a^{n} G_{i, t}^{n}
\end{aligned}
$$

com a restrição de que (para ambos os tipos de P\&D) para um $\omega$ arbitrariamente grande,

$$
\forall G_{i}>0 \exists \delta>0 \mid\left\{1-\operatorname{Lim}_{G_{i} \rightarrow \omega} \operatorname{Pr}(d=1)\right\} \geq \delta
$$

Um sucesso imitativo automaticamente garante à firma incorporar ao seu estoque de capital a produtividade da melhor técnica utilizada na indústria. Obter um sucesso inovador implica acessar uma tecnologia cuja produtividade não é conhecida previamente, mas é resultado de um processo estocástico. Neste sentido, há dupla incerteza nesse processo inovador: por um lado, o comprometimento permanente das firmas com uma política de gastos em P\&D não garante que algum sucesso tecnológico será obtido; por outro, mesmo que a firma obtenha um sucesso inovador, o resultado alcançável (o

$6 P\left(\right.$.) é uma medida de probabilidade; $a_{i t}$ é um parâmetro setorial indicador do grau de oportunidade e $d$ é uma variável binária do tipo Bernoulli com um parâmetro $p$ de sucesso e (1-p) de fracasso, cujo subscrito mais à frente, $n$ ou $m$, indica se se trata de inovação ou imitação, respectivamente. $F_{G}($.$) é uma função de$ distribuição acumulada da variável aleatória $G$, que indica o gasto necessário para obter um sucesso inovador ou imitativo. 
nível de produtividade) pode estar aquém do nível prevalecente de produtividade da firma. Se $d^{n}=1$, a produtividade a ser obtida, $\Phi_{i t}$, é uma variável aleatória que possui distribuição $\log$ normal cuja média cresce a uma taxa exógena, ou seja,

$$
F_{\log (\Phi)}=\frac{1}{\sqrt{2 \pi \sigma}} \exp \left\{-(k-\mu(t))^{2} / 2 \sigma^{2}\right\}, k \in \Re
$$

onde $F$ é a função teórica de distribuição acumulada de $\log \Phi$, donde segue que

$$
\begin{aligned}
& \log \left(\Phi_{i t}\right) \sim \mathrm{N}(\mu(\mathrm{t}), \sigma 2) \mathrm{e} \\
& \mu(t)=P_{0}(1+\varepsilon t)
\end{aligned}
$$

onde $P_{0}$ é a produtividade inicial e $\varepsilon$ é a taxa de crescimento dessa produtividade por período. A medida do ritmo de expansão da produtividade latente (Nelson e Winter, 1982a, p. 283) é dada pela taxa de crescimento da média dessa distribuição - uma aproximação do ritmo de crescimento das oportunidades tecnológicas impulsionado pelos desenvolvimentos técnicos e científicos exógenos à indústria.

Ao fim do período a firma fará sua escolha tecnológica (a técnica que será utilizada no próximo período) sobre um conjunto de técnicas alternativas, às quais estão associados diferentes níveis de produtividade - a produtividade da técnica "copiada" $\left(\hat{A}_{i t}\right)$, a produtividade obtida por meio do sucesso inovador $\left(\Phi_{i t}\right)$, além da produtividade da técnica até então utilizada pela firma $\left(A_{i(t-1)}\right)$ :

$$
A_{i t}=\operatorname{Max}\left\{A_{i(t-1)}, \hat{A}_{i t}, \Phi_{i t}\right\}
$$

o efeito do progresso técnico empreendido pela firma que obtém um sucesso inovador sobre a produtividade média da indústria é tanto maior quanto maior for seu peso relativo dentro da indústria.

Vale observar que a implicação mais direta dessa "regularidade" nas decisões de investimento em P\&D - já que as firmas permanentemente destinam uma proporção fixa do valor de seu estoque de capital - é que a busca inovadora, em particular, não é um processo passivo de ajustamento compensatório de perdas de participação no mercado ou de modificaçóes nas relações de preço entre os fatores de produção, mas, sim, um instrumento de criação de vantagens competitivas tanto maiores quanto maior o grau de pioneirismo nas descobertas e apropriabilidade de seus resultados - em que pese a incerteza ${ }^{7}$ relativamente maior que cerca decisóes de investimento em P\&D comparadas

7 Há pelo menos dois tipos distintos de incerteza ligados à atividade de $\mathrm{P} \& \mathrm{D}$ : tecnológica - que se refere às conexões entre P\&D e inovação e depende tanto da natureza do processo inovador pretendido (radical ou incremental) quanto das potencialidades da tecnologia que está sendo explorada pelas firmas; e de mercado - que afeta as ligaçóes entre investimento em P\&D e competitividade da firma e está relacionada ao impacto que a inovação terá sobre as preferências dos agentes. Para mais detalhes, cf. Oltra e Yildizoglu (1988, seções 1 e 3$)$. 
às decisões de produção e investimento em expansão de capacidade produtiva. Não se quer dizer com isso que se trata de uma decisão de natureza totalmente subjetiva produto de algum tipo de animal spirits - nem exclusivamente restrita aos aspectos estritamente técnicos envolvidos no processo de inovação, mas, certamente, uma combinação de ambos que envolve ainda condições institucionais; depende, assim, basicamente de três elementos:

(a) de uma avaliação das potencialidades de aprendizado e dos ganhos cumulativos da inovação - que podem permitir incrementos na sua capacidade inovadora e permitir avançar mais rapidamente em uma trajetória tecnológica;

(b) das condições de apropriabilidade dos resultados da inovação, isto é, dos mecanismos que permitem algum grau de "exclusividade" na exploração desses resultados. Essa avaliação depende, basicamente, de dois elementos: (i) da existência de regras institucionais que regulem direitos de propriedade (sistema de patentes), e (ii) das condições propriamente tecnológicas que podem, pela complexidade envolvida, dificultar ou retardar o processo de difusão da inovação por imitação - o que significaria uma diluição mais lenta da rentabilidade extra proveniente da inovação selecionada pelo mercado;

(c) do custo e das dificuldades envolvidas no processo inovador decorrentes do estado atual do conhecimento científico na(s) área(s) mais relevante(s) para o desenvolvimento tecnológico da indústria em questão.

Por fim, o modelo NW possui um terceiro módulo que especifica as decisões de investimento (bruto) da firma. A decisão de ampliação da capacidade produtiva depende funcionalmente de três elementos: (1) do mark-up da firma (razão entre preço e custo unitário de produção), (2) da parcela de mercado que possui e (3) da lucratividade, que indiretamente afeta a capacidade de investimento da firma por meio das limitações de financiamento que pode impor. O investimento é limitado superiormente por uma restrição financeira determinada exclusivamente pelo lucro líquido da firma $\left(\pi_{i, t}^{l}\right)$ e inferiormente por uma condição de não-negatividade, a saber, que os investimentos sejam, no mínimo, suficientes para a reposição das máquinas e equipamentos depreciados; desse modo, a taxa de investimento máximo será dada por:

$$
I_{i, t}^{\max }=d+\pi_{i, t}^{l}+\max \left\{0, b \pi_{i, t}^{l}\right\} b \geq 0
$$

onde $d$ é taxa de depreciação do estoque de capital e $b$ é o coeficiente bancário que indica o número máximo de unidades de crédito que a firma pode dispor, para cada unidade de lucro líquido por unidade de capital, para financiar suas decisóes de investimento. A taxa desejada de investimento (bruto), por sua vez, é dada por: 


$$
I_{i, t}^{*}=d+\left(1-\frac{m_{i, t}}{m_{i, t}^{*}}\right)
$$

onde $m_{i, t}$ é o mark-up efetivo ${ }^{8}$ da firma $i$ no período $t$ e $m_{i, t}^{*}$ é o nível desejado de mark-up que julga compatível com seu peso relativo dentro da indústria no período. Assim, o mark-up desejado deverá refletir, de um lado, as limitaçôes colocadas pelo efeito adverso que uma expansão desmedida (em um contexto onde a demanda é constante e tem elasticidade unitária) da firma teria sobre sua própria lucratividade - expressas em seu market share, $s_{i t}$, de outro, os impulsos subjetivos que levam a firma a tomar suas decisões de investimento menos baseadas em uma avaliação prospectiva das condições de demanda e mais em seu próprio senso de oportunidade na exploração das oportunidades de lucro que a expansão do estoque de capital pode, num contexto de interdependência, permitir - essencialmente pelos efeitos cumulativos que possui sobre a capacidade inovadora/imitativa das firmas. Tem-se então que,

$$
m_{i, t}^{*}=\frac{2 \varphi-s_{i, t}}{2 \varphi-2 s_{i, t}}
$$

onde $\varphi$ indica o grau de "agressividade" ${ }^{9}$ das estratégias de investimento da firma (suposto igual a 1$)$.

Segue então que a taxa de investimento efetiva da firma $i$ no período $t$ será dada por:

$$
I_{i, t}=\max (0, z) \text { onde } z=\min \left\{I_{i, t}^{\max }, I_{i, t}^{*}\right\}
$$

assim, a posição do estoque de capital da firma no período seguinte será dada por:

$$
K_{i(t+1)}=K_{i t}\left(1+I_{i t}-d\right)
$$

donde segue trivialmente que $I_{i, t}>d \rightarrow K_{i, t+1}>K_{i, t}$.

A primeira restrição (financeira), contida em (10), dependendo da estrutura do mercado, pode ter uma implicação decisiva para a sobrevivência das firmas inovadoras, já que o financiamento do investimento é função apenas dos níveis correntes de lucro: uma condição excessivamente restritiva de acesso ao crédito (diminuto coeficiente de empréstimos, $\left.b^{10}\right)$, combinado com uma estrutura de mercado onde a "distribuição"

8 Calculado trivialmente como $m_{i, t}=P_{t} A_{i, t} / c$.

9 Que será tanto maior quanto mais elevado for $\varphi$. A idéia é captar em alguma medida o grau de "cautela" que a firma possui em suas decisões de investimento.

10 O coeficiente de empréstimo $(e)$ nada mais é do que o número máximo de unidades de crédito $(E)$ que é possível obter para cada unidade de lucro líquido por unidade de capital. As simulações originais do modelo NW foram feitas para dois tipos de regime creditício, definidos pelo valor do coeficiente de empréstimo $(e), 1$ e 2 . 
da demanda se dá entre um grande número de firmas, pode implicar um potencial de lucratividade aquém daquele necessário para permitir à firma "deslocar" sua restrição financeira e ampliar seu estoque de capital, afetando diretamente sua probabilidade de sucesso inovador. Restaria à firma, para tentar "sobreviver", abandonar os investimentos em P\&D, caso contrário, a manutenção de rotinas tecnológicas - que exijam elevado comprometimento das receitas - sob essas condições a tornaria ilíquida o suficiente para que fosse "expulsa" do mercado.

\section{LIMITAÇÕES E PROBLEMAS INTERNOS AO MODELO NELSON-WINTER}

O modelo NW apresenta algumas deficiências e limitações - em geral, decorrentes da forma simplista como descreve certas hipóteses - que, obviamente, não comprometem o poder da teoria e sua evidente inovação conceitual.

Primeiro, cabe observar que o modelo, por supor que as firmas vendem toda a produção (as firmas operam sempre em plena capacidade ${ }^{11}$ ), ignora as implicações intertemporais dos ajustamentos realizados no início de cada período (quando, é razoável supor, são revisadas as decisões de investimento e, por extensão, de produção e preço no modelo) sobre as decisões de produção e investimento nos períodos subseqüentes, induzidos pela realização de um valor de vendas diferente dos valores esperados quando do cálculo de produção empreendido pela firma. É como se supusesse, à la Keynes, que as expectativas de venda sempre se confirmam ${ }^{12}$ - ou seja, que toda a produção é realizada. É curioso, pela própria importância que os desequilíbrios, mesmo de curto prazo, possuem dentro do enfoque evolucionário neo-schumpeteriano, que os autores tenham ignorado os efeitos de indução da demanda sobre a dinâmica das firmas e tenham tornado o mark-up efetivo (razão preço-custo) e o market share das firmas as variáveis que, de forma exclusiva e sobrecarregada, determinam as decisões de expansão e contração (vide equação em (11)).

Segundo, a ausência de defasagens na função investimento das firmas, implicando, de forma completamente irrealista, que os acréscimos de capacidade produtiva planejados pelas firmas ficam imediatamente disponíveis no mesmo período em que tal decisão é

11 "A firm uses its best technique to the maximum level permitted by its existing stock of capital, purchasing needed complementary inputs on factor markets." (Nelson e Winter, 1982, p. 281).

12 Mas note-se que em Keynes - diferentemente do que ocorre no modelo NW - existe um processo gradualista e contínuo de revisão das decisões de produção que, por suposição simplificadora, não produz alterações nos níveis de produção e preço determinado pela firma - o que, aliás, sempre deu margem a interpretações de que se trataria de um equilíbrio entre demanda e oferta. Mas o uso dessa hipótese decorria de seu interesse maior em demonstrar a possibilidade de ocorrer desemprego com "equilíbrio" e, por isso mesmo, deixando de lado a discussão sobre os efeitos dinâmicos das divergências entre valor de vendas previsto (produção e preços) e valor de vendas realizadas; Cf. Possas (1986). 
realizada - aspecto que, aliás, já foi apontado, por exemplo, por Possas (1988) e Andersen (1996). Vale observar também que o modelo trabalha com um estoque homogêneo de capital, o que permite que o desempenho produtivo de novos equipamentos/ técnicas introduzidas por meio da atividade de P\&D (sucesso imitativo ou inovador) possa ser estendido a todo o estoque de capital da firma.

Terceiro, o modelo possui uma representação "ortodoxa" do processo de formação de preços - determinado pelo equilíbrio entre a oferta e demanda agregada da indústria -, ignorando uma tradição teórica mais próxima do enfoque pretendido que utiliza o princípio do custo total, esquema mais adequado até por se tratar de uma indústria em condições oligopolistas, onde é razoável esperar que os preços praticados pelas firmas concorrentes exerçam alguma influência sobre o cálculo de preços da firma.

Quarto, a ausência de alguns feedbacks básicos, em particular, a inexistência de um mecanismo de correção adaptativa das estratégias tecnológicas (expressas na política de P\&D da firma) em função do seu desempenho competitivo. Como foi visto acima, no modelo NW as firmas seguem regras simples de gasto em P\&D: investem uma fração fixa de seu estoque de capital. É possível argumentar, em defesa desse procedimento, que a rigidez da estratégia de investimento em P\&D é uma prática defensiva motivada pela não-estacionariedade do ambiente econômico e pela incerteza dos resultados da atividade inovadora e refletiria mesmo a inércia das rotinas organizacionais. Todavia, a ausência de um mecanismo de adaptação decisória que seja sensível aos resultados efetivos obtidos pela firma viola não só o conteúdo processual da racionalidade ${ }^{13}$ empre- $^{-}$ gada pelas firmas, como, também, simplifica excessivamente o que seria uma aplicação modelística da noção de racionalidade limitada ${ }^{14}$ (ver Simon, 1987).

É verdade que uma das principais contribuições da extensão do modelo NW proposta por Winter (1984) - além de incorporar ao modelo a entrada de novas firmas e permitir a análise de diferentes regimes tecnológicos (fontes de inovação) - foi a introdução de uma espécie de "aprendizado comportamental" por meio de mecanismos que modificam as estratégias de busca tecnológica das firmas. Mas vale observar que conquanto

13 Comportamentos racionais no sentido processual exigem, pelo menos, dois requisitos: (1) resultar de uma deliberação apropriada a partir dos meios que se julgam adequados; e (2) incorporar mecanismos que permitam uma "realimentação" contínua das decisões a partir dos resultados obtidos. Sobre esse processo de ajustamento, Pondé (2000, p. 31 ) observa: "Este feedback, por sua vez, desencadeia um processo pelo qual o agente avalia criticamente os procedimentos em uso e os altera quando julga necessário, de maneira que um processo de aprendizado torna os procedimentos em uso um resultado da história de decisóes e interaçóes com o ambiente por aquele vivenciada."

14 Sobre a regra de investimento em P\&D empregada no modelo de Nelson e Winter (1982) Oltra e Yildizoglu (1998) comentam: "This is of course very far from Simon's initial propositions." Uma tentativa de justificar essa rigidez da regra de gasto em P\&D - como sendo uma aproximação razoável da inércia existente nas rotinas organizacionais - pode ser encontrada em Dosi, Marengo e Fagiolo (1996, p. 64). 
o mecanismo utilizado ${ }^{15}$ resolva o problema da rigidez da política de P\&D das firmas no modelo NW - e a implicação (i)lógica dali derivada de que o desempenho da firma (insatisfatório) não produz uma revisão das estratégias das firmas percebidas como mais diretamente ligadas ao seu desempenho competitivo -, não deixa de ser uma regra conservadora, já que apenas um mau desempenho é considerado um estímulo apropriado (triggering effects) para acionar um procedimento automático de revisão estratégica. Uma sugestão para enriquecer a regra é introduzir ajustamentos mesmo quando o desempenho da firma está acima do "nível de aspiração", como forma de incorporar uma certa "agressividade" estratégica da firma em explorar suas vantagens competitivas sinalizadas por algum indicador de seu desempenho (e.g. a taxa de crescimento de sua participação de mercado).

Por fim, cabe notar que pela sua estrutura unissetorial o modelo não possui ligações que permitam capturar os efeitos (e.g. multiplicadores) sobre as decisões de produção e investimento das firmas decorrentes de mudanças nos coeficientes técnicos de produção e consumo ocorridas nos demais setores - pelo menos os mais diretamente vinculados à indústria em questão.

15 Os ajustes nas decisões de gasto em P\&D seguem uma regra tipo satisficing: se a variável que indica o desempenho da firma, $X_{i, t}$ (uma distribuição defasada do lucro), está abaixo do nível de aspiração considerado satisfatório para a firma - o lucro médio da indústria -, a firma fará modificações marginais em suas decisões de gasto em P\&D; os ajustamentos "estratégicos" são desencadeados apenas nesse caso.

Formalmente: seja o seguinte evento $L_{\Pi}=\left[X_{i, t}<\bar{\Pi}_{t}\right]$ (a performance da firma é menor que o retorno médio da indústria) e denominemos por $\Gamma_{L_{\Pi}}$ (.) uma tunção indicadora do evento tal que $\Gamma_{L_{\Pi}}(w)=1$ se $w \in L_{\Pi} \mathrm{e}$ $\Gamma_{L_{\Pi}}(w)=0$ se $w \in L_{\Pi}^{c}$, onde $w$ pode ser interpretado como o resultado da variável performance no período $t$. Detinido os valores iniciais que indicam as estratégias de P\&D das firmas e seu estoque de capital, fica também determinado os valores médios da indústria (ponderado pelo peso relativo do estoque de capital de cada firma) das estratégias de P\&D por unidade de capital $\left(\bar{r}_{t}^{n} \mathrm{e} \bar{r}_{t}^{m}\right)$; a revisão das estratégias de cada firma é feita segundo as seguintes regras:

$r_{i(t+1)}^{n}=\left\{\left(1-\Gamma_{L_{\Pi}} b\right) r_{i t}^{n}\right\}+\left\{\left(\Gamma_{L_{\Pi}} b\right) \bar{r}_{t}^{n}\right\}+\Gamma_{L_{\Pi}} u_{i t}^{n}$ onde $u_{i t}^{n} \sim N\left(0, \sigma^{n}\right)$

para o P\&D inovador e, semelhantemente,

$r_{i(t+1)}^{m}=\left\{\left(1-\Gamma_{L_{\Pi}} b\right) r_{i t}^{m}\right\}+\left\{\left(\Gamma_{L_{\Pi}} b\right) \bar{r}_{t}^{m}\right\}+\Gamma_{L_{\Pi}} u_{i t}^{m}$

para P\&D imitativo, onde $u_{i t}^{m}$ é também uma variável aleatória i.i.d. Ambas as regras indicam que se a performance da firma $X_{i, t}$ estiver abaixo do seu nível de aspiração, isto é, se $\Gamma_{L_{\mathrm{n}}}(w)=1$, a firma ajusta sua política de gasto em $I^{\prime} \propto D$ em direção aos valores médios da indústria, caso contrário, repete no período seguinte a mesma estratégia utilizada no período anterior. 


\section{MECANISMOS DE REALIMENTAÇÃO DO PROCESSO DE BUSCA TECNO- LÓGICA: "MARKET FEEDBACKS" E A QUESTÃO DA CUMULATIVIDADE TECNOLÓGICA}

A formalização do processo de mudança tecnológica (equações em (5) e (6)) foi o "módulo" analítico presente no modelo NW que mais influenciou a representação análoga em outras versões de modelos evolucionários de dinâmica industrial. Sua "transmissão" parece ter passado incólume às modificaçôes analíticas realizadas, pelos modelos mais recentes, em outras representaçôes contidas no modelo NW, o que acabou por transferir a esses modelos pelo menos parte das limitaçóes aí presentes (cf. Almeida, 2003, p. 22-77). Ainda que aqui pretendamos discutir mais pormenorizadamente apenas as limitaçôes ligadas à ausência de cumulatividade tecnológica no modelo, é possível apontar outras limitações do processo de busca tecnológica do modelo $^{16}$ e mesmo uma série de extensões factíveis do modelo NW. ${ }^{17}$

No modelo NW (e mesmo em outros modelos de competição com inovação endógena que seguem, na formalização do processo de busca tecnológica, sua formulação) não há um processo de realimentação estritamente tecnológico, isto é, um mecanismo de realimentação (self-reinforcement) da busca tecnológica que derive exclusivamente do sucesso inovador/imitativo ${ }^{18}$ alcançado pela firma em períodos prévios e cujo benefício produzido, é razoável admitir, venha ser tanto maior quanto mais recentes forem os êxitos obtidos das estratégias tecnológicas.

Convém esclarecer que, analiticamente, pode-se dizer que existe cumulatividade em um processo intertemporal $\{x\}_{t}$ que pode gerar resultados $y$ ou $z$ se houver um processo $p$ de intensidade maior (path-dependent) ou menor, que realimenta os resultados de $\{x\}$ em $t+i(i=1, \ldots, n)$ em direção a um dos resultados possíveis ( $y$ se $p=p_{y}$ ou

$z$ se $p=p_{z}$, digamos), de modo que

16 Ver nota 3. Um modelo de busca tecnológica que procura superar as deficiências do modelo NW ali apontadas pode ser visto em Almeida (2003).

17 Há pelo menos outros três elementos que podem ser colocados no modelo: primeiro, introduzir a influência do histórico financeiro da firma e da estrutura de sua dívida (passivo) sobre sua capacidade de endividamento corrente e, por extensão, sobre suas decisões de investimento. Segundo, amparado por uma teoria mais geral de portfólio, introduzir outras opções de valorização do capital que não apenas a aquisição de máquinas e equipamentos visando à ampliação de sua capacidade produtiva. Terceiro, incorporar a já bastante difundida característica da atividade inovadora empreendida pelas firmas, a saber: que grande parte dos esforços de P\&D são direcionados não para a inovação de processos, mas para as atividades de modificação dos atributos tecnológicos dos produtos (inovação de produtos).

18 É razoável também estendermos essa cumulatividade para as firmas que, por propensão a risco menor ou por possuir "expectativas tecnológicas" pouco otimistas com relação às oportunidades tecnológicas existentes, consideram mais vantajoso investir em capacitaçóes e em um tipo de conhecimento interno mais apropriado para "copiar" tecnologias de fronteira na indústria. 


$$
\operatorname{Pr}\left(\{x\}_{t+1}=y \mid p=p_{y}\right)>\operatorname{Pr}\left(\{x\}_{t+1}=y \mid p=p_{z}\right) .
$$

Nosso argumento, portanto, é que a formalização da busca tecnológica não captura o efeito da cumulatividade dos avanços tecnológicos - uma importante propriedade da atividade de P\&D e do próprio aprendizado tecnológico ${ }^{19}$-, o que analiticamente significaria que o aumento da probabilidade de ter sucesso tecnológico não está diretamente ligado aos resultados das estratégias tecnológicas das firmas (ver (5) e (6)). Da forma como foi descrito por Nelson e Winter (1982a, cap. 12), apenas a magnitude do gasto em P\&D influencia as chances de sucesso inovador e imitativo; ou seja, se supusermos, por simplificação, que $G_{i t}^{n}=G_{i(t-1)}^{n}$, e ainda que nos restringíssemos apenas aos resultados mais recentes da busca inovadora $\left(d_{i(t-1)}^{n}\right)$, fica valendo a igualdade abaixo

$$
\operatorname{Pr}\left(d_{i t}^{n}=1 \mid d_{i(t-1)}^{n}=1\right)=\operatorname{Pr}\left(d_{i t}^{n}=1 \mid d_{i(t-1)}^{n}=0\right)
$$

o que claramente negligencia a influência da acumulação de conhecimento e da competência tecnológica da firma expressa no desempenho (sucessos e fracassos obtidos) passado de suas estratégias tecnológicas. ${ }^{20}$ É verdade, todavia, que existe no modelo NW uma realimentação positiva do potencial inovador/imitativo da firma, mas ela não é tecnológica, isto é, ela não é diretamente derivada do sucesso tecnológico prévio, ${ }^{21}$ mas, sim, uma realimentação repleta de mediações que passam pelo mercado e a tornam, ao fim de tudo, muito mais próxima de uma espécie de market-feedback. ${ }^{22}$ Vejamos mais de perto a questão.

A vantagem corrente que a firma inovadora/imitadora bem-sucedida no passado pode possuir no presente (e que seria expressa por uma probabilidade maior de ter sucesso tecnológico, mas a partir do gasto em P\&D corrente da firma) depende dos resultados que serão obtidos pelas demais firmas e, ao fim de tudo, de como essas mudanças irão afetar o preço na indústria; havendo resultados que favoreçam a firma bem-sucedida

19 Dosi, Marsili, Orsenigo e Salvatore (1995, p. 418 passim).

20 Sobre a cumulatividade ligada à influência que o histórico tecnológico da firma deve ter sobre o resultado de suas estratégias tecnológicas veja-se, por exemplo, Dosi, Marsili et al. (1995, p. 419), Nelson (1995, p. 50), Dosi (1991, p. 81), Dosi (1997, p. 1534), Malerba e Orsenigo (2000, p. 302) e Possas (1989, p. 171). Esse último, por exemplo, no trecho citado afirma que "o prêmio 'schumpeteriano' pela liderança bemsucedida na inovação pode ser alto e dar lugar a vantagens rapidamente cumulativas." Malerba e Orsenigo, no trecho citado, observam que as condiçôes de cumulatividade de um regime tecnológico estabelecem que "current innovative firms are more likely to innovate in the future in specific technologies and along specific trajectories than non-innovative firms."

21 O que, de resto, está claro nesta passagem em que Nelson e Winter (1982, p. 310) afirmam que "The probability that a firm will come up with an innovation is proportional to its RerD spending and hence to its size; thus, large firms have a higher probability of coming up with a new technique in any period, and on average they tend to be closer to the frontier of techniques..."

22 Ou uma espécie de efeito-tamanho como parece sugerir Coombs (1988, p. 299); entretanto, a distinção é aqui essencialmente semântica. 
no passado e permitam uma expansão do seu estoque de capital (que deve, logicamente, ser relativamente maior do que aquela que as firmas que não obtiveram sucesso antes farão), só agora e assim é que o modelo garantirá, sob tais circunstâncias, uma realimentação do processo de busca tecnológica da firma e que, em última instância, deriva do resultado (sucesso ou fracasso) que obteve no passado recente. Mas o que sustentamos é que essa cumulatividade é de natureza distinta e não deriva direta e exclusivamente do sucesso inovador/imitativo alcançado pela firma em períodos prévios. $\mathrm{O}$ tipo de cumulatividade que existe no modelo $\mathrm{NW}$, não bastasse derivar em grande parte da rigidez das estratégias de $\mathrm{P} \& \mathrm{D}$ - já referida anteriormente -, tem por trás um ciclo de mediações que, decerto não seja instantâneo, possui um timing provavelmente mais longo e carregado de condicionantes (descritos logo acima e que são atenuados pela hipótese de elasticidade unitária - que permite com que a distribuição das vantagens de custo recaia preponderantemente sobre os preços) do que aquele que possa estar implícito no mecanismo de realimentação que estamos propondo aqui de natureza tecnológica - e que não exclui ou invalida aquele.

Desse modo, a ausência de cumulatividade tecnológica no modelo NW decorre do fato de o investimento corrente em P\&D - uma parcela do estoque de capital da firma - ser o determinante exclusivo da probabilidade de sucesso tecnológico das firmas: a experiência obtida e a "eficiência" com que a firma alocou os recursos que destinou para a atividade de P\&D ao longo de toda a sua trajetória de operação no setor não exercem influência direta no desempenho tecnológico subseqüente da firma.

Uma reformulação analítica desse aspecto implicará ampliar os elementos que influenciam o processo inovador/imitativo de forma a produzir uma desigualdade estrita na equação acima, capturando, assim, os efeitos dos ganhos de aprendizado decorrentes da cumulatividade da atividade de busca tecnológica; assim, seria correto que

$$
P\left(d_{t}^{n}=1 \mid d_{t-i}^{n}=1\right)>P\left(d_{t}^{n}=1 \mid d_{t-i}^{n}=0\right) \forall i=1, \ldots, n
$$

e mais geralmente

$$
\operatorname{Pr}\left(d_{t}^{n}=1 \mid d_{t-i}^{n}=1\right)>\operatorname{Pr}\left(d_{t}^{n}=1 \mid d_{t-j}^{n}=1\right) \forall i<j
$$

Assim, se definirmos $\Psi_{i}=\left\{t ; d_{i, t}^{n}=1\right\}$ e $\Psi_{j}=\left\{t ; d_{j, t}^{n}=1\right\}$ como sendo conjuntos compactos que representam, respectivamente, a coleçao de períodos, ao longo da trajetória de operação da firma $i$ e $j$, que indicam os momentos em que sua busca inovadora foi bem-sucedida, ainda que as firmas $i$ e $j$ tenham sido bem-sucedidas em seus lances inovadores um número equivalente de vezes, isto é, que $\#\left(\Psi_{i}\right)-\#\left(\Psi_{i}\right)=0$, suas probabilidades de sucesso inovador podem ser diferentes, ou seja, $P\left(d_{i, t}^{\text {inov }}=1\right) \neq P\left(d_{j, t}^{\text {inov }}=1\right)$. 
A introdução desses aspectos requer a redefinição da estrutura de probabilidades que define o sucesso inovador/imitativo das firmas de modo a introduzir a influência positiva dos resultados anteriores nos resultados dos "lances" (draws) correntes - ou seja, uma fonte de cumulatividade essencialmente tecnológica já que ligada à influência que a "memória” inovadora/imitativa da firma tem, a cada período, sobre sua função de distribuição de probabilidade. A próxima seção se ocupará de introduzir mudanças que possam dar conta desses aspectos no modelo NW.

\section{COMPETÊNCIA TECNOLÓGICA: INTRODUZINDO CUMULATIVIDADE TECNOLÓGICA}

Ao introduzir cumulatividade pretendemos tornar o potencial inovador/imitativo (doravante tecnológico apenas) de uma firma $i$ que foi relativamente mais bem-sucedida em suas estratégias no passado do que a firma $j$, maior do que o potencial detido pela firma $j$, de modo que

$$
\operatorname{Pr}\left(\tilde{d}_{i, t}^{n}=1 \mid \tilde{d}_{i, t-k}^{n}=1\right)>P\left(\tilde{d}_{j, t}^{n}=1 \mid \tilde{d}_{j, t-m}^{n}=1\right) \forall k<m
$$

implicando que o potencial tecnológico da firma $i$ será tanto maior (supondo $G_{i, t}=G_{j, t}$ ) quanto mais recentes forem os resultados positivos de suas estratégias vis$\grave{a}$-vis à tirma $j$, que a despeito de poder também deter o mesmo número de sucessos inovadores/imitativos prévios, os obteve em períodos menos recentes. Deste modo, introduzir um mecanismo que faça valer a desigualdade (18) (inclusive para um número maior de sucessos no passado) significará tornar o processo de busca tecnológica das firmas rigorosamente path-dependent; mas não apenas porque seus resultados passam a depender do histórico tecnológico da firma, mas porque, combinado com o tipo de cumulatividade que está associada ao efeito do sucesso tecnológico da firma sobre seu estoque de capital e, por conseguinte, sobre seu gasto em P\&D (cujas mediaçóes foram descritas sumariamente acima), existirá um forte processo dinâmico de realimentação (positiva) dos seus resultados e, portanto, do próprio processo de mudança técnica na indústria. A fim de incorporar esses aspectos, é preciso definir uma variável que possa ponderar os resultados das estratégias tecnológicas que as firmas mantiveram, de maneira que, em relação ao período corrente $t$, os resultados em $t-1, t-2, \ldots k, \ldots, 1$ tenham uma importância decrescente na formação de um indicador que permita produzir uma correlação serial nos resultados das estratégias tecnológicas ao longo do tempo.

Nesse sentido, é possível definir $I_{i, t-k}^{\tilde{d}}$ como um indicador da importância relativa do resultado da estratégia tecnológica no $(t-k)$-ésimo período - onde $k=1, \ldots, t-1-$ 
para o sucesso da busca tecnológica no período corrente $t$ que possuam a seguinte propriedade:

$$
I_{i, t-k}^{\tilde{d}}>I_{i, t-2}^{\tilde{d}}>\ldots>I_{i, 2}^{\tilde{d}}>I_{i, 1}^{\tilde{d}}
$$

Embora essas características sejam importantes, é preciso complementá-las com outras num mecanismo que possa ampliar o potencial tecnológico das firmas além daquele que prevaleceria para um mesmo montante de gasto em P\&D e nenhuma estratégia tecnológica bem-sucedida no passado.

Para o cômputo do que será chamado, em seguida, "competência tecnológica" das firmas na indústria, e incorporando as características da expressão em (19), vamos definir $\varphi_{i, t-k}$ como função inversa do tempo, de modo que:

$$
\varphi_{i, t-k}=\frac{1}{\sqrt{k}}\left(1-\hat{i} \sum_{l=1}^{k-1} \tilde{d}_{i, t-k+l}\right) ; k=1, \ldots, t-1
$$

onde a expressão entre parênteses ${ }^{23}$ indica que o "peso" do resultado da estratégia tecnológica da firma $i$ no período $t-k$ poderá ser menor $(0<\hat{i}<1)$, além do que seria apenas pela sua posição no intervalo de tempo transcorrido, pelo fato de a firma ter obtido um número maior ou menor de sucessos subseqüentes. Isso estaria indicando que a firma está em nova fase de sua trajetória tecnológica e que, portanto, aquele resultado é relativamente menos importante (dependendo do parâmetro $\hat{i}$ ), dada a sua atual posição na trajetória, até porque as capacitações e o conhecimento tecnológico requeridos para avançar na presente fase (se distinta) podem ser relativamente mais complexos do que os requeridos no período $t-k$.

Há, portanto, duas idéias contidas na expressão em (20). Em primeiro lugar, que os sucessos mais recentes são mais importantes para a firma e são indicadores mais robustos do domínio das fases da trajetória tecnológica que percorreu; segundo, é preciso, com base nesse critério, diferenciar a competência tecnológica de firmas que, não obstante as diferenças quanto ao período em que obtiveram sucesso, lograram o mesmo número de "sucessos" inovadores ou imitativos - de maneira a evitar o viés que existiria caso a "competência tecnológica" fosse dada apenas pelo porcentual de "lances" bem-sucedidos.

É possível agora definir o histórico tecnológico da firma $i$ no período $t$ como sendo

$$
\mathrm{H}_{t}^{i}=\sum_{k=1}^{t-1} \varphi_{i, t-k} \cdot \tilde{d}_{i, t-k}
$$

23 Definiremos, por convenção, para o caso em que $k=1$, que $\tilde{d}_{i, t}=0$. 
que assumirá, por exemplo, valor zero se as estratégias tecnológicas da firma $i$ não foram bem-sucedidas. Assim, combinando as expressões em (20) e (21), é possível definir

$$
\theta_{i, t}=\frac{\mathrm{H}_{t}^{i}}{\sum_{k=1}^{n} \varphi_{i, t-k}}
$$

como sendo a "competência tecnológica" da firma $i$ no mesmo período; este seria um indicador de competência que reflete o domínio que a firma possui da trajetória tecnológica, onde $0 \leq \theta_{i, t} \leq 1$. Resta agora utilizar essa formulação para garantir certas propriedades ao processo (redefinido) de mudança tecnológica da firma no modelo NW.

\subsection{Redefinindo o Primeiro Estágio do Processo de Busca Tecnológica}

O processo que define o resultado das estratégias tecnológicas das firmas (inovadoras e imitadoras) continuará seguindo, na forma, o tratamento existente no modelo NW (cf. Nelson e Winter, 1982a, cap. 12): um processo estocástico em dois estágios onde, no primeiro, se define o sucesso ou fracasso da estratégia (imitação ou inovação) e, no segundo, a produtividade que será alcançada. A proposta analítica acima esboçada servirá para que reformulemos o primeiro estágio desse processo, o que significará modificar as equações (5) e (6) do modelo original de modo a abrir espaço para as relaçôes expostas em (18).

Como, seja no caso da firma inovadora, seja no caso imitadora, as equaçóes são muito semelhantes, sempre que possível, nos referiremos apenas a um caso. Assim, indo direto ao ponto, a probabilidade de obtenção de um lance inovador (ou imitativo) será função $(\Theta: \Re \times \Re \rightarrow[0,1])$, além do gasto corrente em P\&D $\left(G_{i t}^{n}\right)$, da "competência tecnológica" da firma $\left(\theta_{i, t}\right)$, variável acima definida que procura refletir o domínio da firma ao longo da trajetória tecnológica. Ou seja,

$$
\operatorname{Pr}\left(d_{t}^{n}=1\right)=\Theta\left(G_{i t}^{n}, \theta_{i t}\right)
$$

tal que

$$
\frac{\partial \Theta}{\partial G}>0 ; \frac{\partial \Theta}{\partial \theta}>0
$$

Assim, para o caso das firmas inovadoras, segue então que 


$$
\operatorname{Pr}\left(\tilde{G}<G_{i, t}^{n}\right)=F_{\tilde{G}}\left(G_{i, t}^{n}\right)=1-\exp \left\{-\left(1+\theta_{i, t}\right) a^{n} G_{i, t}^{n}\right\}
$$

que indica a probabilidade de a firma inovadora, realizando um gasto em P\&D inovador no período $t$ de $G_{i, t}^{n}$, obter um sucesso inovador; observe-se que para a firma que imita a expressão é a mesma, substituindo-se apenas $G_{i, t}^{n}$ por $G_{i, t}^{m}$ e o parâmetro $a^{n}$ por $a^{m}$ - parâmetros que permitem especificar o grau de oportunidade tecnológica, respectivamente, da inovação e da imitação na indústria, definido exogenamente e compartilhado igualmente pelas firmas do setor -, de maneira que $a^{n}>a^{m}$, donde segue que, se fizermos a firma $i$ inovadora e a firma $j$ imitadora, e sendo $\theta_{i, t}=\theta_{j, t}$, segue que

$$
F_{\tilde{G}}\left(G_{i, t}^{n}\right) \geq F_{\tilde{G}}\left(G_{j, t}^{m}\right) \quad \forall \quad G_{i, t}^{n}=G_{j, t}^{m},
$$

onde $\widetilde{G}$ é o valor do gasto em P\&D que seria necessário no período para produzir um sucesso em sua respectiva estratégia tecnológica - que é estocástico e segue uma distribuição exponencial. Mesmo que um e outro tipo de firma possam se beneficiar mutuamente do esforço tecnológico de firmas que possuem direcionamento distinto do seu, ${ }^{24}$ é razoável admitir que a probabilidade inicial de obter sucesso em suas respectivas estratégias é diferente em um caso e outro, sendo maior no caso das firmas inovadoras - daí a diferença nos parâmetros $a^{n}$ e $a^{m}$. Há duas razões inter-relacionadas para tanto: (1) no caso das firmas que procuram inovar (stricto sensu), os resultados não são tão diretamente acessíveis e por isso mesmo estão expostos a uma incerteza maior (ainda que inicialmente): o sucesso inovador não garante que a firma irá obter um equipamento cuja produtividade seja maior do que aqueles que ela já utiliza; (2) as firmas que inovam comprometem um volume proporcionalmente maior de recursos com sua atividade de P\&D; desse modo, por (1) e (2), é a diferença na probabilidade de obter sucesso em sua estratégia, vis-à- vis ao caso das firmas imitadoras, que justifica e torna legítima a existência de firmas cujos processos de busca seguem orientações distintas. $^{25}$

Para o caso em que as firmas $i$ e $j$ compartilham do mesmo tipo de estratégia tecnológica (P\&D imitativo, suponhamos), fica valendo a seguinte desigualdade:

24 As inovadoras, porque as firmas que procuram imitar podem fornecer indicações de aperfeiçoamentos tecnológicos em seu próprio equipamento não percebido durante a fase de elaboração do projeto, ou mesmo porque algumas firmas imitadoras podem deter uma tecnologia superior à sua; as imitadoras, por sua vez, porque as firmas inovadoras possuem as capacitaçôes tecnológicas que permitiram obter a tecnologia que elas (as imitadoras) desejam copiar; de firmas do mesmo tipo porque pode haver um grau razoável de complementaridade/sinergias, já que compartilham do mesmo tipo de orientaçáo estratégica do ponto de vista tecnológico.

25 Cf. Nelson e Winter (1982, cap. 12 e 13) e Caccomo (1996). 


$$
\operatorname{Pr}\left(d_{i, t}^{m}=1 \mid G_{i, t}^{m}=G_{0}\right)>\operatorname{Pr}\left(d_{j, t}^{m}=1 \mid G_{j, t}^{m}=G_{0}\right)
$$

desde que $\theta_{i, t}>\theta_{j, t}$.

Vale lembrar ainda que a expressão (24) tanto contempla o mesmo tipo de cumulatividade do modelo $\mathrm{NW}^{26}$ como também possui as seguintes propriedades necessárias:

$$
\begin{aligned}
& 0 \leq F_{\tilde{G}}\left(G_{i, t}\right) \leq 1 \\
& \lim _{G_{i} \rightarrow+\infty} F_{\tilde{G}}(.)=1 \text { e } \lim _{G_{i} \rightarrow-\infty} F_{\tilde{G}}(.)=0 \\
& G_{i, t}>G_{i, t}^{\prime} \rightarrow F_{\tilde{G}}\left(G_{i, t}\right) \geq F_{\tilde{G}}\left(G_{i, t}^{\prime}\right)
\end{aligned}
$$

Assim, de modo análogo ao que foi feito em Possas, Koblitz et al. (2001, p. 358), o resultado (sucesso ou fracasso) do primeiro estágio do processo de busca tecnológica da firma (obtenção de novas tecnologias/equipamentos ou por imitação (m) ou por inovação $(\mathrm{n})$ ) será definido como uma variável aleatória discreta que assume valor 1 ou 0 conforme o seguinte processo:

$$
d_{i, t}^{n}=1 \text { se } Z \leq 1-\exp \left\{-\left(1+\theta_{i, t}\right) a^{n} G_{i, t}^{n}\right\}
$$

ou

$$
d_{i, t}^{n}=1 \text { se } Z>1-\exp \left\{-\left(1+\theta_{i, t}\right) a^{n} G_{i, t}^{n}\right\}
$$

onde $Z \sim U[1,0]$. Vale lembrar que o sucesso inovador permite obter uma tecnologia cuja produtividade não é previamente conhecida, sendo determinada como uma variável aleatória com distribuição lognormal (equações em 7 e 8). O sucesso da firma imitadora permite acesso à tecnologia disponível com maior produtividade na indústria isto é, na fronteira tecnológica atual do setor, mas não necessariamente na fronteira tecnológica que pode ser alcançada.

26 Como já fora comentado, originalmente no modelo NW o sucesso tecnológico abre espaço para a obtenção de vantagens competitivas que podem permitir à firma ampliar seu estoque de capital, permitindo, portanto, ampliar os recursos dedicados ao esforço de P\&D; a cadeia de eventos formada por vantagens competitivas, lucros e crescimento se realimentará continuamente, ainda que com intensidade provavelmente decrescente imposta pelas condições de demanda e pelas reações de suas rivais (por impor restrições, em última instância, sobre suas estratégias de curto prazo de lucratividade e crescimento). 
Essa reformulação deverá tornar o modelo mais sensível a feedbacks importantes, abrindo espaço para o aparecimento de novas fontes dinâmicas de assimetrias entre as firmas e para uma realimentação mais forte do processo de busca tecnológica.

A princípio, poder-se-ia pensar que a influência dos resultados anteriores das estratégias tecnológicas da firma nos resultados correntes impõe um viés intertemporalmente irreversível nos potenciais resultados das firmas tecnologicamente bem-sucedidas (inicialmente), donde os resultados observáveis nos períodos subseqüentes seriam apenas "mais do mesmo". Há pelo menos três observações a serem feitas sobre essa possível implicação: em primeiro lugar, que a "irreversibilidade" da vantagem inicial obtida é possível, mas depende em grande medida das parametrizaçóes (da importância desse efeito no sucesso da busca inovadora das firmas) que serão utilizadas nos exercícios de simulações; segundo, e talvez mais importante, deve-se notar ainda que as vantagens associadas aos resultados de P\&D obtidos no passado se diluem ao longo do tempo (ver equação em 22), isto é, o simples transcurso do tempo produz uma deterioração na influência sobre o presente que os resultados das estratégias tecnológicas no passado têm, tanto mais intensa quanto mais distante temporalmente do período corrente estão os resultados; é como se supuséssemos que a "memória tecnológica" da firma sofresse algum tipo de interferência na evocação do conhecimento mais antigo como resultado de um "efeito deslocamento" (crowding out) que as novas informaçóes e tecnologias têm sobre as mais antigas.

\section{SIMULAÇÕES COMPARADAS: FIRMAS INOVADORAS VERSUS FIRMAS IMITADORAS}

Os resultados das simulações que serão apresentados pretendem avaliar preliminarmente a trajetória de algumas variáveis características da dinâmica industrial - market share, preço e produtividade, índice de concentração - a partir de uma extensão do modelo Nelson-Winter que, a nosso ver, agora incorpora um elemento característico do processo de mudança tecnológica (capacidade inovadora/imitativa da firma é correlacionada intertemporalmente) e, mais geralmente, dos padrões de competição do tipo schumpeteriano - em que mover preços e quantidades não são as únicas estratégias de concorrência. Vale mencionar que algumas variáveis do modelo, como é comum, não possuem ainda uma contrapartida empírica que possa ser usada numa eventual análise de aderência dos resultados do modelo. Contudo, dado o objetivo estritamente teórico desse trabalho, indicar proxies para essas variáveis não será uma preocupação na análise dos resultados.

A indústria é composta de oito firmas divididas em dois grupos: quatro firmas inovadoras e quatro firmas imitadoras. À exceção dessa orientação quanto à incorporação de 
tecnologia, as firmas compartilham as mesmas características iniciais. As numeradas de 1 a 4 são inovadoras e gastam $6 \%$ do faturamento em P\&D; as numeradas de 5 a 8 são imitadoras e gastam $3 \%$ em P\&D. Assume-se que cada período de produção equivale a um "trimestre", de maneira que serão feitas simulações para 100 períodos de produção (“time-steps" do modelo), ou 25 “anos”. Seguindo a especificação original, nossas simulações referem-se ao caso do regime tecnológico science-based, em que a fronteira tecnológica (ou, segundo os autores, a "produtividade latente") cresce 1\% por período de produção; ou seja, a média da distribuição lognormal que indicará a produtividade que a firma inovadora bem-sucedida poderá obter cresce $1 \%$ a cada período.

Há, fundamentalmente, duas razôes que motivam o uso das simulaçôes. Em primeiro lugar, a possibilidade de observar e avaliar com detalhe as implicaçôes intertemporais de uma representação teórico-analítica de um sistema econômico ou de uma parte sua, em que seja possível não apenas postular relações complexas entre um número arbitrariamente grande de variáveis, mas também observar fenômenos dinâmicos emergentes da interação desses elementos - e que, de outro modo, seriam dificilmente deduzidos de representaçôes estáticas. Segundo, a possibilidade de realizar uma análise dinâmica sem que isso implique fazer uso de hipóteses demasiadamente simplificadoras que possam descaracterizar o(s) objeto(s) em análise: o uso das simulaçóes não apenas permite reproduzir e analisar cenários que, apenas com muita raridade, teriam a possibilidade de ser empiricamente observados, como também dispensa a busca por soluções matemáticas sistêmicas que sejam generalizáveis; mas dispensa porque, de um lado, incorpora elementos estocásticos que tornam virtualmente infinito o conjunto de soluçôes mutuamente consistentes entre as equações do modelo; de outro, porque o interesse está na obtenção de trajetórias e suas características mais evidentes, logo, na evolução de estados pelos quais passam os agentes (e sua estrutura de referência, e.g., a indústria) a cada período: o interesse está em como se desenvolve o processo de transição entre estados (o estabelecido inicialmente e aquele em que se encontra o sistema $n$ períodos depois, podendo $n$ ser definido arbitrariamente).

As firmas inovadoras obtiveram um market share relativamente mais elevado no contexto em que há cumulatividade tecnológica (29\% contra $18 \%$ no último período sem cumulatividade tecnológica), beneficiando-se relativamente mais por algum tempo de sua estratégia tecnológica. O desempenho desse grupo de firmas, não obstante as diferenças entre elas, permaneceu ainda bastante inferior ao grupo de firmas imitadoras, e isto basicamente porque as vantagens que a cumulatividade tecnológica foi capaz de conceder inicialmente a essas firmas não foi capaz de compensar os custos relativamente maiores do tipo de esforço tecnológico que realiza em relação ao grupo de firmas imitadoras. Como as firmas seguem regras fixas de gasto em P\&D, o impacto que as inovações possuem sobre o preço no setor parece ter comprometido a lucratividade das 
firmas inovadoras - que incorrem em custos maiores -, afetando de modo adverso sua taxa de investimento a ponto de não permitir a consolidação da posição relativamente melhor no mercado obtida inicialmente. A alteração mais significativa que a mudança introduzida no modelo Nelson-Winter parece ter produzido foi de fato na participação de mercado das firmas, produzindo uma reversão significativa das trajetórias desenhadas a partir de certo período - o que não ocorre no contexto sem cumulatividade, onde prevalece a posição permanentemente inferior das firmas inovadoras; entretanto, ambas as estratégias mostram-se eficazes para garantir a sobrevivência das firmas na indústria.

FIGURA I - MARKET SHARE

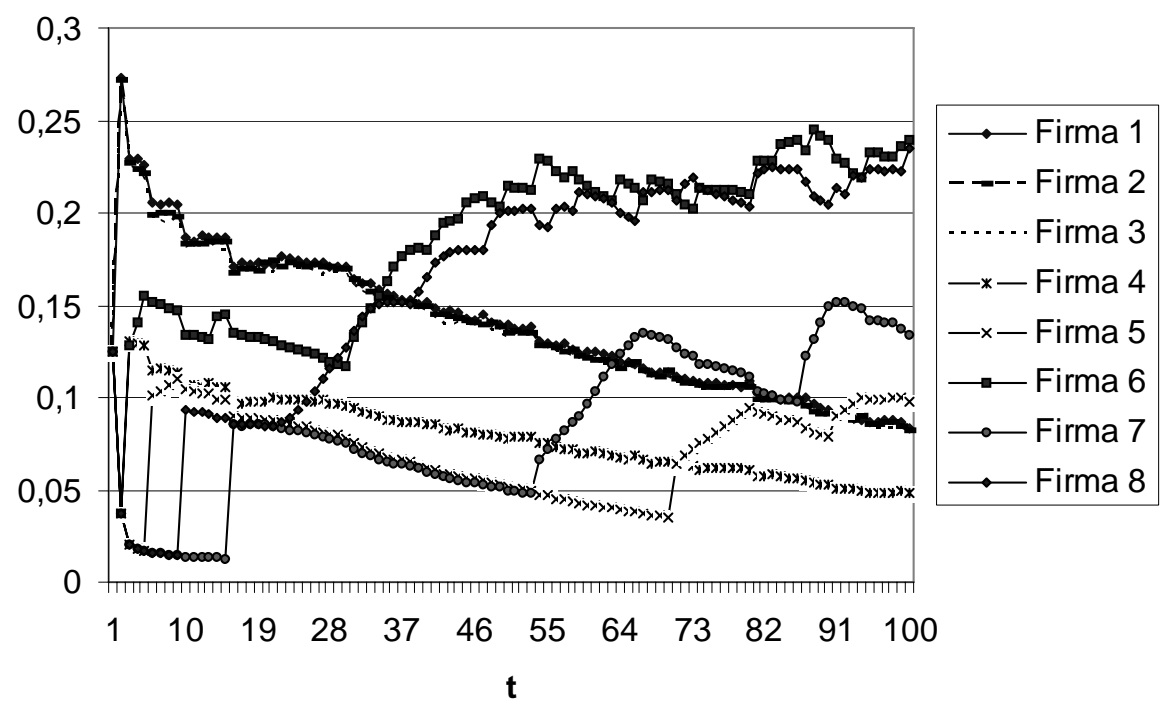

A introdução de cumulatividade também produziu efeitos significativos sobre a trajetória do preço praticado na indústria (Figura 2); as simulações realizadas indicaram que os preços exibem, como esperado, trajetórias declinantes mais acentuadas, uma vez que a presença de cumulatividade, mediado pelo seu impacto sobre a taxa de investimento das firmas, afetou a capacidade produtiva das firmas, fazendo crescer relativamente rápido a capacidade produtiva do setor. O nível de preço prevalecente ao final das simulações é ligeiramente menor na presença de cumulatividade. 
FIGURA 2 - PREÇO

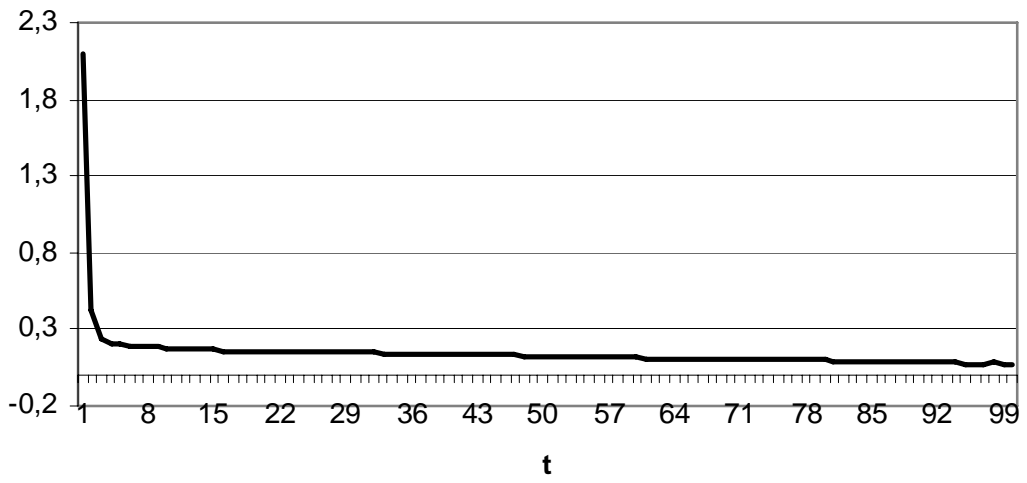

A produtividade (Figura 3) apresentou trajetória crescente na forma de "degraus". Nos períodos em que a produtividade permaneceu constante, as firmas não obtiveram nenhum sucesso inovador ou imitativo, que tendem a impulsionar a produtividade. Não há diferenças significativas em relação às simulações da versão original do modelo: as firmas inovadoras seguem os deslocamentos da fronteira tecnológica com pequena defasagem, enquanto as firmas imitadoras, embora alcancem a melhor tecnologia ("best practice") existente no setor, devido ao menor nível de "oportunidade tecnológica" (parâmetro $a_{m}$ ) que usufruem, seguem a fronteira com uma defasagem relativamente maior vis-à-vis às firmas inovadoras.

\section{FIGURA 3 - PRODUTIVIDADE}
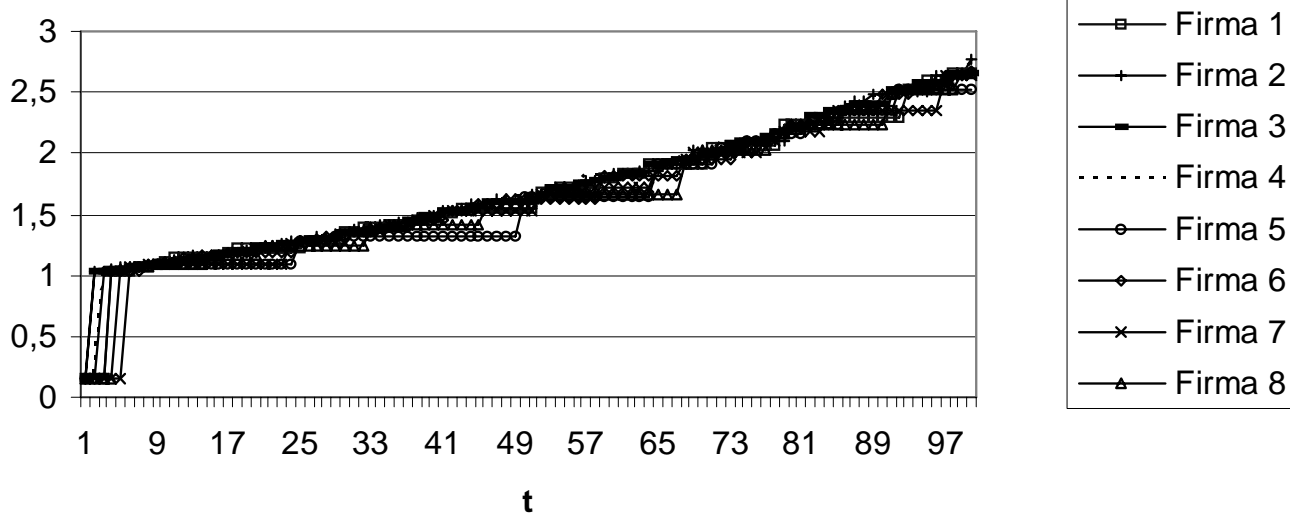
Como a taxa de crescimento da fronteira tecnológica é relativamente baixa (1\%), o grau de concentração - indicado pelo índice de Hirschman- Herfindahl invertido ${ }^{27}$ do mercado permanece relativamente estável, como pode ser visto na Figura 4. Como foi indicado nas simulaçôes preliminares do modelo Nelson-Winter modificado, o crescimento da fronteira tecnológica aumentava o grau de concentração da indústria em benefício das firmas inovadoras - já que, por definição, são as únicas capazes de, a depender dos resultados de suas estratégias tecnológicas, alcançar sistematicamente a fronteira tecnológica. O aumento dessa taxa tende a aumentar o "lag" tecnológico entre imitadoras e inovadoras e criar uma "bifurcação" nas trajetórias de ambas em termos de market share em favor das inovadoras. A presença de cumulatividade tecnológica, pelo melhor desempenho que permitiu das firmas inovadoras, produziu uma distribuição da demanda entre as firmas menos assimétrica.

FIGURA 4 - HHI

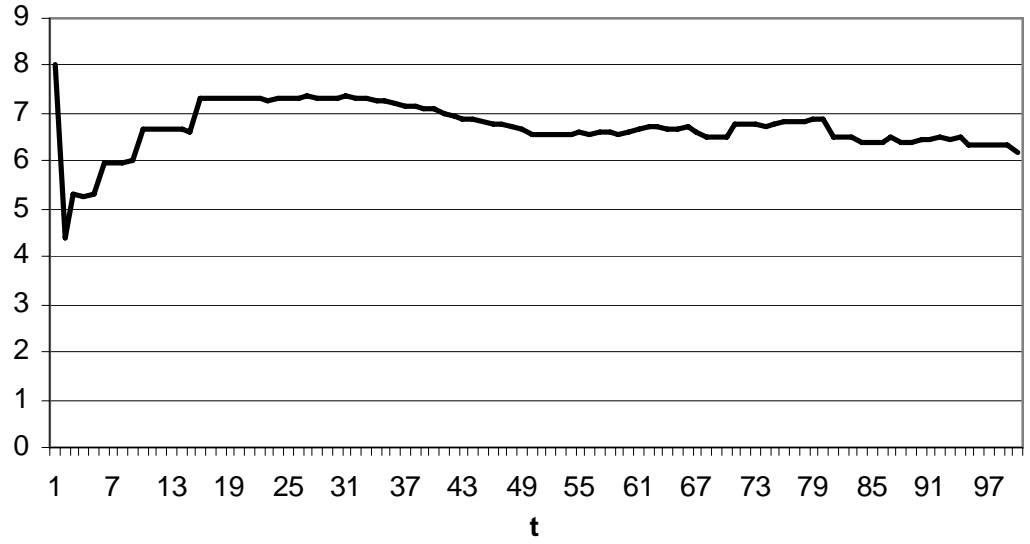

Por fim, vale observar que, como era esperado, o desempenho das firmas em termos de market share está correlacionado diretamente com seu nível de "competência tecnológica". No entanto, ainda que as firmas inovadoras tenham exibido maior domínio da trajetória tecnológica percorrida, mantendo níveis maiores exatamente porque o intervalo de tempo entre os sucessos consecutivos de suas estratégias tecnológicas era relativamente menor do que aquele observado entre as firmas imitadoras, as desvantagens de custo acabaram se impondo a partir de certo período, voltando a prevalecer o desempenho relativamente melhor das firmas imitadoras em termos de market share.

27 Esse índice indica o número de firmas que possuem o mesmo tamanho que produziria um índice de Hirschman-Herfindahl de mesmo valor. Quanto menor este valor, maior é a concentração da indústria. 


\section{FIGURA 5 - COMPETÊNCIA TECNOLÓGICA}

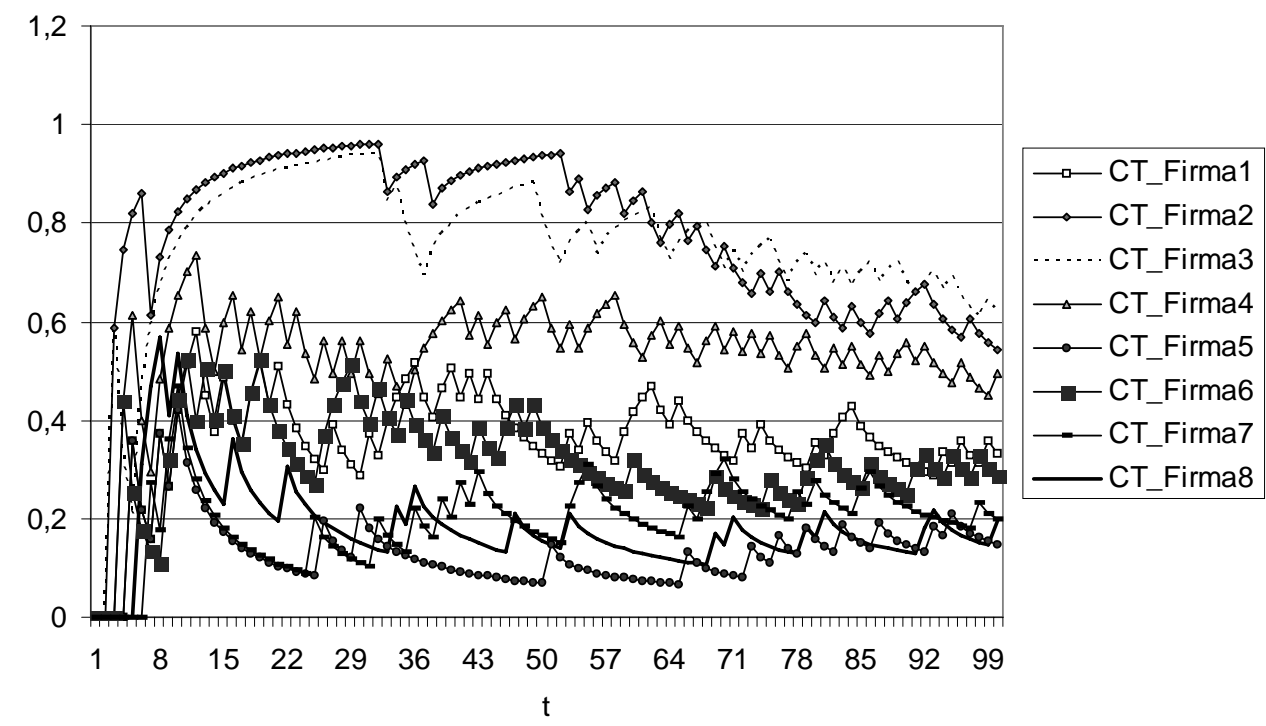

\section{CONCLUSÕES}

O objetivo do artigo foi aperfeiçoar um dos modelos evolucionários de dinâmica industrial de maior influência, incorporando aspectos (cumulatividade tecnológica) apontados como fato estilizado na literatura sobre inovação. A partir dessa motivação teórica propusemos uma redefinição formal relativamente simples do processo de busca tecnológica das firmas de maneira a introduzir feedbacks sobre o "potencial" inovador/imitativo das firmas a partir de uma medida de competência tecnológica que avalia todo o histórico de resultados alcançados. Tal medida considera não apenas o número relativo de sucessos, mas a própria distribuição intertemporal dos resultados, o que permitiu tornar o processo de mudança técnica na indústria rigorosamente pathdependent - fato estilizado da literatura sobre inovação (cf. Redding, 2002; Breschi, 2000).

Alguns resultados podem ser destacados a partir das simulaçóes realizadas, ainda que, vale notar, com cautela porque a robusteza desses resultados carece ainda de mais exercícios de simulação explorando novos intervalos paramétricos, estruturas de mercado iniciais distintas e mesmo novas combinaçôes estratégicas entre as firmas quanto ao montante e à alocação dos gastos nos tipos possíveis de P\&D - se não para qualificar os resultados já encontrados, pelo menos para fornecer novos insights sobre a relação entre a estrutura do mercado e o desempenho de firmas sistematicamente envolvidas na atividade de P\&D. Assim, os exercícios de simulação do modelo Nelson-Winter assim modificado permitiram inferir que a cumulatividade de natureza tecnológica tende 
a funcionar como força estabilizadora (temporária) do desempenho das firmas que obtiveram vantagens iniciais. Porém, o fato de terem seu efeito gradualmente reduzido implica que firmas com sucessos recentes podem se beneficiar disso mais do que firmas que possuem melhor histórico tecnológico, mas com um perfil desfavorável pela não recentidade dos resultados favoráveis que computa. Numa estrutura de mercado relativamente concentrada (8 firmas) e com firmas seguindo estratégias simples de P\&D alocando seu gasto ou em P\&D inovador ou apenas imitativo, e em montantes distintos num caso e noutro -, a existência de cumulatividade tecnológica permitiu que as firmas inovadoras, tomadas em conjunto, obtivessem um desempenho, em termos de market share, relativamente melhor.

Firmas inovadoras ganharam algum destaque inicial em seu desempenho competitivo: as desvantagens de custo foram, durante algum tempo, mais que compensadas pelas vantagens que o sucesso inovador permitiu, o que não foi suficiente para impedir que as firmas imitadoras as ultrapassassem, basicamente pela vantagem que possuem de poderem estar na fronteira tecnológica do setor, incorrendo em custos menores. Aliás, essa vantagem inicial ficou evidenciado no gap tecnológico inicialmente mais acentuado em favor das firmas inovadoras, logo diluído pelos sucessos tecnológicos de algumas firmas imitadoras (6 e 8) que conseguiram acompanhar mais de perto as firmas inovadoras bem-sucedidas. Ainda assim, ambas as estratégias são funcionais para garantir a sobrevivência das firmas.

Por fim, a extensão do modelo Nelson-Winter permitiu observar também que a cumulatividade tecnológica pode garantir um grau mais elevado de rivalidade entre as firmas, o que ficou indicado pelo grau de concentração ligeiramente menor observado ao fim das simulações, ainda que, inicialmente, a cumulatividade tecnológica tenha acentuado as assimetrias iniciais em favor das firmas inovadoras, gerando, com isso, um nível de concentração relativamente maior quando comparado à trajetória análoga na versão original do modelo.

\section{REFERÊNCIAS BIBLIOGRÁFICAS}

Alchian, A. A. Uncertainty, evolution and economic theory. Journal of Political Economy, LVIII, p. 211-221, June 1950.

Almeida, S. Dinâmica industrial e cumulatividade tecnológica. 26 Prêmio BNDES de Economia. Rio de Janeiro: Departamento de Comunicação e Cultura do BNDES, 2004.

Andersen, E. S. Evolutionary economics: post-Schumpeterian contributions to evolutionary economics. London: Pinter, 1996. 
Arthur, B. Self-reinforcing mechanisms in economics. In: Anderson, P. W., Arrow, K. (eds.), The economy as an evolving complex system. 1987. Mimeografado.

Breschi, S.; Malerba, F; Orsenigo, L. Technological regimes and Schumpeterian patterns of innovation. Economic Journal, v. 110, n. 463, pages 388-410, 2000.

Caccomo, J. Technological evolution and economic instability: theoretical simulations. Journal of Evolutionary Economics, v. 6, n. 2, p.141-155, 1996.

Chiaromonte, F.; Dosi, G. The microfoundations of competitiveness and their macroeconomic implications. In: The models revolution, 1991, p. 107-134.

Coombs, R. Technological opportunities and industrial organization. In: Dosi, G.; Silverberg, G. et al., Technical change and economic theory. London: Pinter Publishers, 1988.

Dosi, G.; Marsili, O.; Orsenigo, L.; Salvatore, R. Learning, market selection and the evolution of industrial structures. Small Business Economics, v. 7, n. 6, p. $411-436,1995$.

Dosi, G. The Research on innovation diffusion: an assessment. In: Dosi, G. Innovation, organization and economic dynamics. London: Edward Elgar, 1991, p.115-143.

. Opportunities, incentives and collective patterns of technological change. The Economic Journal, 107, p.1530-1547, Sept. 1997.

Dosi, G.; Marengo, L.; Fagiolo, G. Learning in evolutionary environments. Technical Report 5, CEEL (Computable and Experimental Economics Laboratory), 1996.

Gort, M.; Wall, R. A. The evolution of technologies and investment innovation. The Economic Journal, p. 741-757, 1996.

Kay, N. The R\&D function: corporate strategy and structure. In: Dosi, G.; Freeman, C. et al. (org.), Technical change and economic theory. London: Pinter Publishers, 1988.

Kwasnicki, W. Innovation regimes, entry and market structure. Journal of Evolutionary Economics, v. 6, n. 4, pages 375-409, 1996.

Malerba, F.; Orsenigo, L. Knowledge, innovative activities and industrial evolution. Industrial and Corporate Change, v. 9, n. 2, p. 289-314, 2000.

Nelson, R.; Winter, S. G. An evolutionary theory of economic change. Cambridge: Belknap Press, 1982a.

. The Schumpeterian tradeoff revisited. American Economic Review, v. 72, n. 1, pages 114-12, $1982 \mathrm{~b}$.

. Firm and industry response to changed market conditions: an evolutionary approach. Economic Inquiry, v. 18, n. 2, pages 179-202, 1980.

. Forces generating and limiting concentration under Schumpeterian competition. Bell Journal of Economics, RAND, v. 9, n. 2, pages 524-548, 1978. 
. Toward an evolutionary theory of economic capabilities. American Economic Review, v. 63, n. 2, pages 440-49, 1973.

Nelson, R.; Winter, S.; Schuette, H. Technical change in an evolutionary model. Quarterly Journal of Economics, v. 90, n. 1, pages 90-118, 1976.

Oltra, V.; Yildizoglu, M. Learning and expectations in R\&D decisions. Working Papers Beta-theme (UMR n. 7522 - CNRS), PEGE, Strasbourg: Université Louis Pasteur, 1998.

Pondé, J. L. de Souza. Processos de seleção, custos de transação e a evolução das instituições empresariais. 2000. Tese (Doutorado), Campinas (SP).

Possas, M. L. Para uma releitura teórica da teoria geral. Pesquisa e Planejamento Econômico, v. 16, n. 2, p. 295-307, 1986.

Em direção a um paradigma microdinâmico: a abordagem neo-schumpeteriana. In: Amadeo, E. (org.), Ensaios sobre economia politica moderna: teoria e história do pensamento econômico. São Paulo: Ed. Marco Zero, 1988.

Possas, M. L.; Koblitz, A. et alii. Um modelo evolucionário setorial. Revista Brasileira de Economia, v. 55, n. 3, p. 333-377, jul./set. 2001.

Redding, S. Path dependence, endogenous innovation, and growth. International Economic Review, v. 43, n. 4, pages 1215-1248, 2002.

Simon, H. A. From substantive to procedural rationality. In: Hahn, F; Hollis, M. (eds.), Philosophy and economic theory. Oxford University Press, 1978.

. Bounded rationality. London: MIT Press, 1987.

Winter, S. G. Schumpeterian competition in alternative technological regimes. Journal of Economic Behavior and Organization, v. 5, p. 287-320, 1984.

Winter, S. G.; Kaniovski, Y. M.; Dosi, G. Modeling industrial dynamics with innovative entrants. Structural Change and Economic Dynamics, v. 11, n. 3, pages 255-293, 2000.

Endereço para contato: 29 Coleby Avenue - Lenton - Nottingham - NG7 2NF - United Kingdom.

E-mail: lexss12@nottingham.ac.uk.

(Recebido em outubro de 2003. Aceito para publicação em agosto de 2005). 